\title{
Towards a Plurilingual Development Paradigm. From Spontaneous to Informed Use of Translation in Additional Language Learning ${ }^{1}$
}

\author{
MARIA GONZÁLEZ DAVIES \\ Universitat Ramon Llull, Barcelona, Spain
}

\begin{abstract}
This paper explores the role played by translation in Additional Language Learning (ALL) as a particular example of Translation in Other Learning Contexts (TOLC), i.e., translation as used in educational contexts other than Translation Studies. The project presented in this paper draws on research and good practices in Translation Studies, Pedagogy, Educational Psychology and Language Acquisition and is framed within a plurilingual development paradigm. The theoretical framework questions a monolingual approach to ALL and considers educational objectives, (language) learning strategies, translation competence, Multi-competence, the Dynamic Model of Multilingualism, Plurilingualism and the Interdependence Hypothesis to favour the connected development of linguistic and mediation skills. The pedagogy adopts a humanistic approach to teaching, teaching for transfer and (socio)constructivism. The paper reports on the second of an ongoing 3-stage study, which was carried out in naturally-occurring groups of 45 undergraduate students (Teacher Training, Psychology and Sport Sciences). In the first stage, the spontaneous use of translation was recorded to identify critical instances of its use in ALL. In the second phase, data regarding the teacher's and students' perceptions and uses of translation were gathered. Finally, following on from the findings of this research, learning material is currently being designed with a view to including translation in Additional Language Learning in an explicit way.
\end{abstract}

Keywords: Translation, Language Learning, Plurilingualism, Connectivism, TOLC.

At the very least, we have a MAD, not a LAD-a 'multilingual acquisition device'. David Crystal, Just a Phrase I'm Going Through. My Life in Language (2009:16).

\section{Introduction}

The point of departure of this paper is the conviction that (a) an optimal use of translation in learning contexts other than Translation Studies has substantial potential and this has, on the whole, been greatly underexploited, ${ }^{2}$ (b) Translation Studies and other fields related to (language) learning can make a valuable contribution in this direction. The main aim of this paper is to contribute to bridging the gap in the literature by taking research and good practices in translation beyond the field of Translation Studies and explore its potential as a skill in its own right as well as a spontaneous or informed learning strategy for the development of (inter)linguistic and

\footnotetext{
${ }^{1}$ The research project was designed by the RG CILCEAL, "Interlinguistic and Intercultural Competence in the Teaching and Learning of Languages", University Ramon Llull, with Dr. Christopher ScottTennent. It was partially funded by the University Ramon Llull: Ajuts URL Suport Grups de Recerca during the years 2009-2010 and 2010-2011. Another funding body is the Catalan Government MQD (Millora de la Qualitat Docent) ref. 2010MQD00139. I would like to thank Richard Samson and Héctor Fuster for their help with editing and statistics.

${ }^{2}$ The use of the L1 and translation in ALL has been systematically rejected by most scholars since the advent of the Direct Method (cf. Hall and Cook 2012). Therefore, exploring whether they are valid learning strategies is not such an obvious endeavour.
} 
intercultural competence in learning contexts that involve languages and cultures in contact.

I suggest drawing a distinction between what may be called Translation in Other Learning Contexts (TOLC), i.e., translation used to acquire linguistic, interlinguistic and intercultural competence in fields other than Translation Studies, and translation used to acquire professional translator competence. Given this general premise, the project presented in this paper draws on Translation Studies, Pedagogy, Educational Psychology and Language Learning. It favours interdisciplinary networking ${ }^{3}$ and explores the perceptions and performance of naturally-occurring groups of 69 undergraduate students at the University Ramon Llull (Barcelona), 24 in the pilot study and 45 in the second stage of the study, the main focus of this article.

\section{Theoretical framework}

\subsection{Why TOLC? From Grammar Translation to Plurilingualism}

Translation and the L1 were largely eliminated in the Direct Method and the Communicative Approach to language teaching despite the fact that "there is no evidence as yet that the L1 should be excluded from the language classroom" (Macaro 2001:534). This exclusion was based on two main assumptions (see Richards and Rodgers 2001/2005, Cook 2010, Cummins 2008, Hall and Cook 2012, Skinner 1985, amongst others):

(1) L2 = L1, i.e., the L2, L3 and so on should be acquired in the same way as the L1

(2) the Interference Hypothesis, i.e., teaching should be carried out in the Additional Language Only to avoid interference (negative transfer) from the other languages known by the learner.

Owing to its absence from the classroom and the repetitive and teacher-centred practices of the Grammar-Translation Method (where decontextualised lists of vocabulary and complex grammatical structures had to be translated) translation was either ignored or regarded as a straightforward one-to-one transference between languages. Its complexity and potential were largely overlooked. Paradoxically, at the same time, translation and related learning strategies appeared in widely quoted taxonomies (O’Malley and Uhl Chamot 1990, Oxford 1990) because, in spite of the prohibition, students were using their previously acquired languages to help them learn a new one. This obliteration or rejection of translation and the L1 can be traced back to the Direct Method, as Cook (2010:20-1) states:

So successful were the Direct Method criticisms of TILT [Translation in Language Teaching] that [...] from the 1990s until very recently, there has been virtually no discussion of it in the mainstream language literature. It is not that it was considered, assessed, and rejected, with reasons given for that rejection, but rather that it was simply ignored.

\footnotetext{
${ }^{3}$ The major theoretical sources are Anderson and Krathwohl 2001, ), Aronin and Singleton 2012 Bloom 1956, Byram 2008, Cohen 2011, G. Cook 2010, V. Cook 2001 2007, Cummins 1984, 2007, 2008, González Davies 2004, 2012a, 2012b, González Davies and Scott-Tennent 2001, 2005, 2009, Herdina and Jessner 2002, House 2009 Kelly 2005, Macaro(2001, 2006 and Skinner 1985.
} 
Other reasons for the proliferation of '(AL) Only' classes range from the economic to the ideological (Cook 2010: xvi,19). However, with globalisation, the rise of international mobility and the realisation that heritage ${ }^{4}$ languages play a key role in language learning and identity issues, the need for linguistically prepared citizens, preferably with good mediation skills such as translation, interpreting, intercultural competence now occupies a privileged position in research and good practices in ALL. We may be moving from '(AL) Only' to '(AL) Mainly' classes where all languages are welcome when used in an informed way (McMillan and Rivers 2011, quoted in Hall and Cook 2012:296). The principles underpinning the Direct Method and monolingual practices in the Communicative Approach are currently being questioned and a new plurilingual paradigm is being put forward to explore how languages are learnt (Aronin and Hufeisen 2009, Aronin and Singleton 2012, Bialystock 2001, 2009, Bialystock and Hakuta 1999, Bialystock, Luk and Kwan 2005, Cohen 2011, G. Cook 2010,Cummins 1979, 1984, 2007, 2008, González Davies and Scott-Tennent 2009, Hamers and Blanc 1989/2000, Herdina and Jessner 2002, House 2009, Kovelman, Baker and Petitto 2008, Pettito 2009).

\subsection{Changing the paradigm: from learning monolingually to learning plurilingually}

Most communities nowadays are plurilingual. ${ }^{5}$ There are few spaces left that are completely monolingual. Therefore, the study of language learning that takes for granted only one mother tongue, or ignores the existence of previously known language(s) has become a questionable approach to our understanding of how languages may be learnt. This focus needs to be replaced by more updated concepts such as the definition of multilinguality provided by Aronin and Ó'Laoire (2004: 17-18, quoted in Aronin and Singleton 2012:80): "We see multilinguality as reflecting origins and ethnic belonging, political affiliations and environmental influences, reference groups, and individual development level and cognitive abilities".

This multilingual perspective moves away from FoF (Focus on Form) and even FoM (Focus on Meaning) approaches to language learning, which do not really allow for plurilinguistic affordances. Also, the terms 'first', 'foreign' and 'second' language are slowly giving way to the more flexible terms 'additional' or 'new' language/s (G. Cook 2010). ${ }^{6}$ These imply that the learners operate in classrooms that are plurilingual spaces where they have more than one language at their disposal. Thus, interlinguistic connections can be established and identities recognized far from strict compartimentalisations. These connections, however, should be informed.

Consequently, many lines of research are open such as AL acquisition, the acquisition of mediation skills, or identity issues related to language/s. The first two areas can be directly related to Translation Studies and it is here that scholars, trainers and professionals can contribute with new insights based on the specific research and practices in the field. After all, translators and interpreters are habitual language learners and mediators, the people who actually put into practice plurilingual learning.

\footnotetext{
${ }^{4}$ Other names in the literature are: L1, mother tongue, native or family language/s.

${ }^{5}$ For a table with the languages spoken in each country, see http://www.infoplease.com/ipa/A0855611.html.

${ }^{6}$ Here, 'additional language/s' is used because it was the term chosen at the outset of our research in 20082009. 'Foreign' or 'second' language are retained when they are used by a specific author.
} 
Plurilingual and complexity-based approaches underlie the theoretical framework put forward for Translation in Other Learning Contexts (TOLC). The following are interdisciplinary findings which highlight the potential offered by translation in ALL.

\subsubsection{Positions regarding the use of $L 1$}

As we are dealing with research into Additional Language Learning, we may identify our standpoint relating to the various positions that Macaro observed with teacher trainees regarding their use of L1 in "second language classes" (2001:535):

(1) Virtual: L1 should be totally excluded from the (foreign language) FL classroom

(2) Maximal: there is no value in the use of L1, but it is unavoidable

(3) Optimal: there may be pedagogical value in using L1 and this should be explored.

Although translation is not mentioned explicitly, we suggest that these positions can also be relevant to studies concerning the use of translation in these contexts. Adapting Macaro's proposal (2001:535), we adopt the Optimal Position and replace "L1 use" with "use of translation". Hence, we maintain that:

There is some pedagogical value in use of translation. Some aspects of learning may actually be enhanced by use of translation. There should therefore be a constant exploration of pedagogical principles regarding whether and in what ways use of translation is justified.

\subsubsection{Anatomical Model of Language and Learning}

Taking the views of Cummins, Vygotsky, Chomsky and Piaget as a starting point for discussion, David Skinner (1985) questions the two basic assumptions of the Direct Method (see section 2.1 above). He explores how these principles are inconsistent with general learning theories. Regarding the work of Piaget, Skinner observes that by treating FL students as if they were in preoperational stages that do not correspond to their actual age, a cognitive repression occurs that reduces the rate of acquisition and may lead to learning regression. As for Vygotsky, by blocking meaning and thought with unknown words that are not explained clearly - e.g., by avoiding the L1, cognitive access is denied and the rate of acquisition - i.e., transfer of concepts, decreases. With regard to Cummins, his distinction between Basic Interpersonal Communication Skills (BICS) and Cognitive Academic Language Proficiency (CALP) (1979) along with his Interdependence Hypothesis (1984) brought about a sea change in understanding how the transfer of underlying knowledge and skills acquired in one language can benefit the acquisition of another. Finally, as regards Chomsky, language equivalence and universal grammar fare better with the Direct Method, but the fact that the learner already has an L1 modulates the paths of acquisition, the speed (rate) and the natural sequencing L2 = L1 (route), if not the sequence itself. Therefore, on the basis of these considerations, it can be affirmed that the rejection of previously acquired knowledge (i.e., L1) hinders the speed, rate and route of AL acquisition as well as negating identity traits and disregarding psychological maturity. 


\subsection{Plurilingualism/Multilingualism}

Beyond the more obvious description of multilingualism as the ability to operate in more than one language, the term is not easy to define. There are issues regarding degree, use, life changing profiles and so on. Even the difference between multi- and plurilingualism is disputed. For instance, within the Common European Framework of Reference for Languages (CEFR) they are differentiated thus:

Plurilingualism differs from multilingualism, which is the knowledge of a number of languages, or the co-existence of different languages in a given society [...] languages and cultures are not kept in strictly separated mental compartments, but rather build up a communicative competence to which all knowledge and experience of language contributes and in which languages interrelate and interact (Council of Europe 2001:4).

This paper uses the term 'plurilingualism' and considers translation to be a key strategy for building (inter)linguistic and intercultural communicative competence. Other authors use the term 'multilingualism' in a similar sense, e.g., Aronin and Singleton (2012:6). Their approach, albeit focused on use rather than learning, is helpful to describe new trends in the field. Especially relevant is their distinction between multilinguality (concerning the individual) and multilingualism (concerning a community) as well as their proposed Dominant Language Constellation (DLC), i.e., the group of languages that are used in everyday life by a society or an individual. They claim that "researching multilingualism through the prism of DLC means considering whole sets as units rather than focusing, one by one, on the specific languages used by given individuals or groups" (Aronin and Singleton 2012:69). We maintain that translation becomes crucial in putting these constellations into contact appropriately.

\subsubsection{The development of intercultural competence and mediation skills}

By intercultural competence and mediation skills we mean the ability to work within more than one culture efficiently and to bridge cultures. Within this perspective, keywords such as 'communication' and 'native speaker proficiency' are giving way to others such as 'mediation' and the 'intercultural speaker' (Council of Europe 2001). Furthermore, definitions of culture have shifted from a Humanistic to an Anthropological perspective, that is, from foregrounding the study of a "cultural heritage" that revolves around cultural objects in the target community such as monuments or canonical literary works, to foregrounding the study of "ways of thinking and doing" related to the participants (subjects) in that community and noticing similarities as well as differences between communities (House 2009:8). This understanding may lead to what Byram $(2008: 36)^{7}$ calls tertiary socialisation, whose goal is not "to replace the familiar with the new" but to "raise questions about one's own culturally-determined assumptions and about the society in which one lives".

\subsubsection{Multi-competence}

Defined by V. Cook $(2001,2007)$ as the knowledge of two or more languages in the same mind, the concept of multi-competence concerns how plurilinguals think and learn

\footnotetext{
${ }^{7}$ For an account of how Translation for Intercultural Competence (TICC) was implemented as part of this project, see González Davies (2011, 2012a).
} 
differently from monolinguals. In line with Bialystock (2001, 2009), Bialystock et al. (1999, 2005), Hamers and Blanc (1989/2000), Kovelman et al. (2008), Pettito (2009) and others, the study of multi-competence shows how bi- and plurilinguals acquire additional skills and know-how that are not purely linguistic, but (in)directly related to successful (language) learning. These may include a) use of lower and higher order thinking skills, i.e., remembering, understanding, applying, analyzing, evaluating and creating (Bloom 1956), b) high proficiency related to language resources, c) understanding that language signs are arbitrary, d) sensitivity to semantic and grammatical (ir)regularities, e) good negotiation skills for diversity of meanings, f) tolerance of ambiguity, g) developed creative and critical thinking skills, g) metalinguistic awareness. Consequently, we may conclude that the positive implications of plurilingualism override possible drawbacks such as interferences or delayed production.

\subsubsection{Connectivism and the Interdependence Hypothesis}

The idea of connectivism assumes that all knowledge is related, hence knowledge regarding languages and cultures. Based on this principle, Cummins (1984) put forward his ground-breaking Common Underlying Proficiency Model or Interdependence Hypothesis in opposition to the then widely accepted Interference Hypothesis which, supported by the L2=L1 paradigm, gave way to immersion theories of language learning. Cummins' Interdependence Hypothesis challenged what he called "the two solitudes assumption", that is, the belief that languages are learnt in isolation and should not be mixed in the learning process. Thus, although it is accepted that interferences exist, the research focus is on how the transfer of L1 knowledge outruns the potential interferential drawbacks in ALL by means of an informed use of plurilingual resources.

\subsubsection{The Dynamic Model of Multilingualism (DMM)}

Developed by Herdina and Jessner (2002), this model is based on dynamic systems theory and applies chaos or complexity theory to multilingual development. That is, it favours a holistic approach to language acquisition that rejects simplification and compartimentalisation. In this model, linguistic, psychological, social and contextual factors interrelate to produce multilingual proficiency. The characteristics that distinguish multilinguals from monolinguals are called M(ultilingualism)-factors and these are related to the notions of multi-competence and connectivism (cf. Aronin and Hufeisen 2009). Translation is hardly mentioned in these studies, probably because Translation Studies scholarship has not influenced the field of language acquisition sufficiently despite the valuable contribution the discipline can offer.

\subsubsection{Language of Thought in Second Language Learning}

Reflection on the most appropriate use of translation in ALL plays a central part in Cohen's (2011) work on strategies in the language of thought. Following Kern (1994, quoted in Cohen 2011:247), Cohen makes a distinction between language of thought and language of reference by studying how learners access their L1 or Lo (Other Language) through mental or conscious translation when learning an Lt (Target language). His main aim is to "distinguish a genuine need for translation from a perceived need [so that] teachers [may] coach learners in ways to make translation a productive tool rather than a perfunctory, overused crutch" (Cohen 2011:269). 


\section{3 (How) can Translation Studies contribute?}

This section sets out to show that pursuing translation competence may make a positive contribution to Additional Language Learning given the affinities of the two areas in terms of broader educational objectives and learning strategies. ${ }^{8}$ Thus, Bloom's taxonomy of educational objectives, frequently quoted taxonomies of ALL strategies and two pedagogically oriented models of translation competence are presented here to show potential correspondences (Table 1). As with any contrived grid, Table 1 does not present an exhaustive correlation or the only possible one. Rather, it is a starting point for discussion and for the design of informed activities. In line with the connectivist and complexity principles underlying the plurilingual paradigm, it is worth pointing out that the categories overlap and connect with each other, hence the use of dotted lines. Likewise, no clear cut one-to-one correspondences can be established between the components

each column.

\footnotetext{
${ }^{8}$ Due to space limitations, only translation is analyzed here.
} 


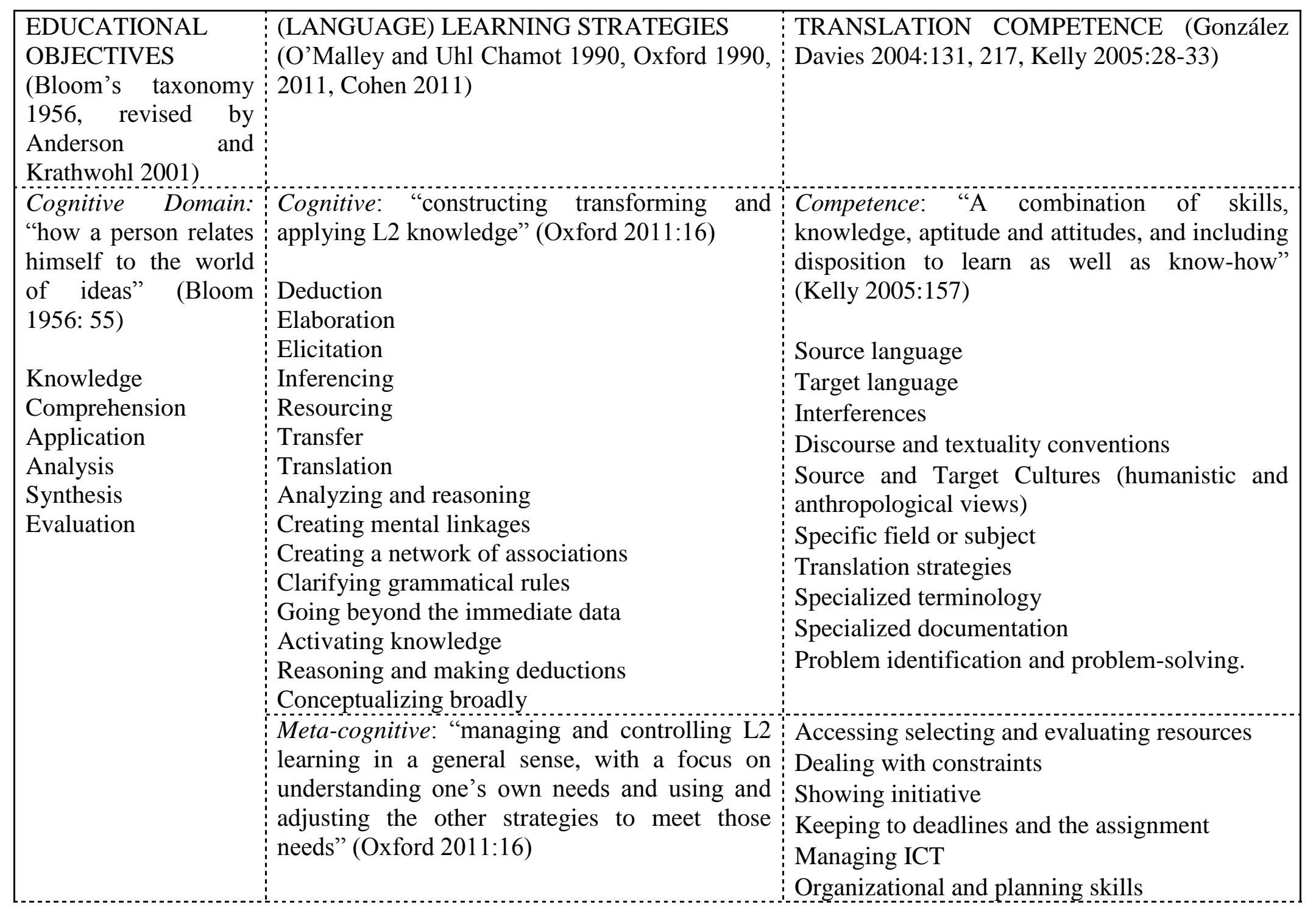




\begin{tabular}{|c|c|c|}
\hline & $\begin{array}{l}\text { Selective attention } \\
\text { Monitoring } \\
\text { Evaluating } \\
\text { Arranging and planning your learning } \\
\text { Checking for comprehension } \\
\text { Checking for certainty: Translating for } \\
\text { verification } \\
\text { Translating for gist } \\
\text { Obtaining and using resources }\end{array}$ & $\begin{array}{l}\text { Self-assessment and revision } \\
\text { Concentration, memory }\end{array}$ \\
\hline \multirow[t]{2}{*}{$\begin{array}{l}\text { Affective Domain: } \\
\text { "how he relates } \\
\text { himself to the world } \\
\text { of people" (Bloom } \\
\text { 1956:55) }\end{array}$} & $\begin{array}{l}\text { Social and Affective: "Handling emotions, } \\
\text { beliefs, attitudes, and motivation in L2 learning" } \\
\text { (Oxford 2011:16) } \\
\text { Questioning for clarification } \\
\text { Cooperating } \\
\text { Self-talk } \\
\text { Lowering anxiety } \\
\text { Empathizing } \\
\text { Making input more user-friendly } \\
\text { Activating supportive emotions, beliefs and } \\
\text { attitudes } \\
\text { Generating and maintaining motivation }\end{array}$ & $\begin{array}{l}\text { Intra and interpersonal skills: } \\
\text { Flexibility and tolerance of ambiguity } \\
\text { Self-concept as language learners } \\
\text { Team work, controlling working constraints } \\
\text { Self-confidence, initiative } \\
\text { Negotiation and leadership skills }\end{array}$ \\
\hline & $\begin{array}{l}\text { Sociocultural-Interactive Dimension:"Dealing } \\
\text { with issues of contexts, communication, and } \\
\text { culture in L2 learning" (Oxford 2011:16) } \\
\text { Overcoming knowledge gaps in communication } \\
\text { Dealing with sociocultural contexts and } \\
\text { identities }\end{array}$ & $\begin{array}{l}\text { Managing values, emotions and beliefs } \\
\text { regarding at least two cultures } \\
\text { Being aware of issues of intercultural } \\
\text { communication and translation as a special form }\end{array}$ \\
\hline
\end{tabular}

Table 1. Correspondences between educational objectives, ALL strategies and translation competencies 


\section{Pedagogical framework for TOLC}

TOLC differs from previous approaches to the use translation in that it:

(1) sets out from the new paradigm of plurilingual development examined in section 2.2 above

(2) draws mainly, but not exclusively, on

2.1 Translation Studies, as well as Linguistics, Educational Psychology and Pedagogy

2.2 Humanistic and socioconstructivist, rather than transmissionist, educational premises

2.3 Connectivism and the Interdependence Hypothesis rather than on the Interference Hypothesis and the compartimentalization of languages (and knowledge in general) in the brain

(3) focuses on the explicit use of translation in ALL (as well as the use of L1 and code-switching)

(4) sets out to explore how translation can improve both general linguistic competence and mediation skills

(5) includes a reflection on how to best relate educational objectives and learning strategies with translation competence so as to improve language learning

(6) views translation as a means of understanding the morphosyntactic, lexicosemantic and/or pragmatic and cultural aspects of a language and perceives translation competence as a set of specific linguistic, encyclopaedic and transferential skills, along with specific intra- and interpersonal skills that may enhance language learning.

The approach to teaching/learning proposed in this study is, therefore, in consonance with the theoretical principles of the plurilingual paradigm. It is inspired by Cummins' (2007) teaching for transfer and includes (socio)constructivist features, attention to diversity, interaction, reflection and self-regulation. Accordingly, it creates a humanistic and collaborative learning environment, where student-student and teacher-student interaction and scaffolding are favoured together with individual tutoring.

\section{The study}

This explorative quasi-experimental study was carried out following grounded theory under the interpretative research paradigm. Statistical analysis was applied to support the findings derived from the qualitative instruments. This mixed approach to record the participants' beliefs, perceptions and use of translation in their learning environments throws more light on the complexity of the results as a whole as defined by Burke et al. (2007:123):

Mixed methods research is the type of research in which a researcher or team of researchers combines elements of qualitative and quantitative research approaches (e.g., use of qualitative and quantitative viewpoints, data collection, analysis, inference techniques) for the broad purposes of breadth and depth of understanding and corroboration. 
This paper reports mainly on the second stage of our project, which took place during the years 2011-2012 and is a refined replication of the initial study that was undertaken from 2008 to 2009 .

\subsection{Context and subject population}

Data were provided by a naturally occurring group of 45 bilingual undergraduate students taking the subject "English B2.1" during one semester, i.e., 15 weeks, 4 contact hours per week. Their mother tongues were Catalan (65\%) and Spanish (35\%), although $100 \%$ used both Catalan and Spanish at university and in their free time. At the onset of the study their English language competence corresponded to the CEFR level B1 (intermediate). Translation was introduced explicitly in a group of 17 students (EG), while data were also gathered in a group of 28 students (CG) where the use of L1 and translation were not allowed. All the participants in this study were informed about the aims of our project and freely consented to providing data.

\subsection{Operative definitions}

The following operative definitions are suggested considering that the study was carried out in a pedagogical context.

Use of L1: use of previously known language(s) shared - or not - by the teacher and the students. It may serve different functions such as giving instructions or reducing anxiety (G. Cook 2010 lists up to 38 functions). According to our findings in the pilot study, "use of L1 and Translation are not interchangeable terms, as each contributes different skills and strategies to the learning of foreign languages" (González Davies 2012b:72).

Code-switching: a spontaneous or planned inter or intra sentential change of linguistic codes with no guiding explicit primary source text (Corcoll 2011).

Translation: here defined as an interlinguistic and intercultural mediation process and product and as a learning strategy to develop both competences. As a process, translation denotes "a dynamic process of communication" (Hatim and Mason 1990:223). As a product, we consider translation to be any text, verbal or visual, that is related to a source text (cf. Shavit 1986/2009). Finally, to differentiate it from codeswitching and the use of L1, we regard translation as an informed change of linguistic code applied consciously to an explicit primary source text (adapted from House 2009, personal communication 2011). The processes expected from the students to produce an appropriate translation were as follows:

- understanding the message and effect of the source text

- relaying the message and effect appropriately according to the conventions of the target community and the assignment

- applying appropriate translation strategies according to familiarity with problem-solving and spotting skills.

\subsection{Research questions}

Three general research questions concerning the potential of TOLC established the framework for the project. They were based on the assumption put forward in the 
literature and confirmed in our pilot study that previously acquired languages are used as a learning device to learn new languages.

General Research Questions for TOLC:

a. Can research and good practices in Translation Studies be transferred to other learning contexts that involve the use of AL?

b. Can translation be used as both a skill and a strategy to improve linguistic, interlinguistic and intercultural competence in other learning contexts that involve the use of AL?

c. Can learning material and procedures such as projects where translation is pivotal be designed to improve linguistic, interlinguistic and intercultural competence in other learning contexts that involve AL?

The data were analysed in order to obtain answers to the following specific questions:

1. When, why and how did these students use L1?

2. When, why and how did these students use translation?

3. How did said uses relate to cognitive, meta-cognitive and socio-affective learning strategies?

4. Which of these uses were perceived by the students to be successful in aiding or improving their ALL process?

A fifth question was investigated in the second stage of our research. It resulted from the findings obtained in the pilot study:

5. Can correspondences be found between translation competence(s), ALL strategies and educational objectives?

A sixth question is to be explored in the last stage of the study as a result of observations and outcomes of the first two stages:

6. How do these perceptions and outcomes correlate with the students' AL performance especially regarding learning material related to the use of translation?

Questions 1, 2, 3, 4 were addressed in the pilot study and are discussed in González Davies and Scott-Tennent (2009) and González Davies (2012b). Here I will report on the research process and findings concerning questions 2,3 , and 4 , as they were investigated in the second stage of our project. Table 1 in section 2.3 above provides some tentative answers to question 5 .

\subsection{Temporization and data-gathering instruments}

There were a total of 65 contact hours, of which 4 were dedicated to planned reflection on translation and translation strategies and 10 to carrying out activities that included translation. The data-gathering instruments were validated in the pilot study. Following Macaro (2006), the indicators were defined as the outward manifestations of perceptions and use of educational objectives, learning strategies and translation competences. 
1. A description of linguistic backgrounds was provided with an itemized rating scale including the domains 'Home and family" and 'Friends and free time'.

2. A questionnaire was used at the beginning and end of the semester (same questionnaire, 24 indicators, 4-point rating scale) to measure the students' perception of own use of L1 and translation and the retrospective assessment of L1 and translation use as experienced in the teaching unit.

3. A self-report was written with each questionnaire ${ }^{9}$ to observe and measure the students'general position on use of L1 and translation, their views on the potential usefulness of L1 and translation, their opinion on potential disadvantages and the reasons for using L1 and translation.

4. Two Individual Written Protocols were submitted with the respective essays, each reporting on the relative frequency of certain specific types of L1 and translation use and the details of one actual case for each of these types (29 indicators).

7. At each session an annotated Teacher's Diary recorded comments on the main aims of the session, the level of achievement, the main tasks and noteworthy aspects regarding L1 and translation use.

8. Seven interactive translation activities ${ }^{10}$ were carried out to record the students' perceptions and use in situ.

The instruments and temporization are summarized in Table 2 below.

\begin{tabular}{|l|l|l|l|}
\hline INSTRUMENTS & TEMPORIZATION (WEEK) & EG & CG \\
\hline Linguistic background & 1 & $\mathrm{~V}$ & $\sqrt{ }$ \\
\hline $\begin{array}{l}\text { Initial questionnaire (IQ) and self-report } \\
\text { (SR) }\end{array}$ & 1 & $\mathrm{v}$ & $\sqrt{ }$ \\
\hline 2 written protocols (WP) & 4,14 & $\mathrm{v}$ & \\
\hline Teacher's Diary (TD) & all & $\mathrm{v}$ & \\
\hline Explicit translation & $\begin{array}{l}\text { Reflection: as needed } \\
\text { Activities: 2, 5, 7, 8, 9,11,14 }\end{array}$ & $\mathrm{v}$ & \\
\hline $\begin{array}{l}\text { Final questionnaire (FQ) and self-report } \\
\text { (SR) }\end{array}$ & 15 & $\mathrm{v}$ & $\sqrt{ }$ \\
\hline
\end{tabular}

Table 2. Instruments and temporization

The data-gathering process complied with two conditions that have increasingly gained priority in the design of our recent studies which are mainly based on participant observation within naturally occurring instructional settings (González Davies and Scott-Tennent 2001, 2005, 2009, Scott-Tennent and González Davies 2008, González Davies 2012b). The conditions are: (a) providing data should be as effortless and natural as possible for the students and (b) as far as possible, the data-gathering processes should be naturally integrated into the instructional process and contribute to learning and/or assessment.

\subsection{Results and discussion}

\footnotetext{
${ }^{9}$ Question for self-report (100 words): "Which do you think is the role of L1 and translation in additional/foreign language learning?".

${ }^{10}$ Due to space limitations, class activities will be described in a future publication.
} 
The results for questions 2 and 3 (see section 4.3 above) are presented together as they were found to be closely related during data collection and analysis.

\subsubsection{Initial questionnaires (IQ) and final questionnaires $(F Q)$}

Two questions (Q), followed by 11 and 13 indicators (I) respectively, were put to the students:

\begin{tabular}{|c|c|}
\hline $\begin{array}{l}\text { Q1. When, Why and How do you use } \\
\text { translation (or searching for an } \\
\text { equivalence of meaning between English } \\
\text { and your mother tongue) when learning } \\
\text { English? }\end{array}$ & $\begin{array}{l}\text { Q2. Please value the contribution of the use } \\
\text { of translation (or searching for an } \\
\text { equivalence of meaning between English } \\
\text { and your mother tongue) on the } \\
\text { additional/foreign language learning } \\
\text { process. }\end{array}$ \\
\hline $\begin{array}{l}\text { I_1 to take notes of the instructions } \\
\text { I_2 to consult a partner } \\
\text { I_3 to consult the teacher } \\
\text { I_4 to self-correct language } \\
\text { I_5 to ensure the retention of a new } \\
\text { linguistic element } \\
\text { I_6 to check some aspect of reading } \\
\text { I_7 to check some aspect of listening } \\
\text { I_8 to check some aspect of writing } \\
\text { I_9 to check some aspect of speaking } \\
\text { I_10 to look up equivalents in a bilingual } \\
\text { dictionary } \\
\text { I_11 to look up equivalents in parallel } \\
\text { texts }\end{array}$ & $\begin{array}{l}\text { I_1 favours the acquisition of an AL } \\
\text { I_2 promotes interaction among peers } \\
\text { I_3 promotes interaction with the teacher in } \\
\text { the classroom } \\
\text { I_4 helps to create a relaxed atmosphere in } \\
\text { the classroom } \\
\text { I_5 helps to improve the level of English } \\
\text { (syntactic) } \\
\text { I_6 helps to improve the appropriate use of } \\
\text { language in different contexts (pragmatics) } \\
\text { I_7 helps to improve knowledge about the } \\
\text { culture of English-speaking communities } \\
\text { I_8 helps to overcome problems of reading } \\
\text { comprehension (reading) } \\
\text { I_9 helps solve problems of listening } \\
\text { comprehension (listening) } \\
\text { I_10 helps to overcome problems of writing } \\
\text { (writing) } \\
\text { I_11 helps to overcome problems when } \\
\text { speaking (speaking) } \\
\text { I_12 helps to better discern the similarities } \\
\text { between languages } \\
\text { I_13 helps to better discern the differences } \\
\text { between languages }\end{array}$ \\
\hline
\end{tabular}

An independent-samples t-test and a paired-samples t-test were conducted to compare between and within groups responses to the questionnaires from EG and CG (see Tables A and B in Appendix I).

Here are the most relevant conclusions derived from the statistical analysis. Both groups set out with a favourable opinion of translation in ALL which, in itself, contradicts Direct Method premises, at least from the students' perspective. Also, although not $100 \%$ significant $(p<0.05)$, the majority of results show a general tendency towards a decrease in the use of translation in the EG, where it was used explicitly. In the initial questionnaire (IQ) these students say that they use more translation (19/24) than those in the CG (5/24). This changes in the final questionnaire (FQ), where the EG say they use 
translation more than the CG in only $5 / 24$ cases. So, an explicit use of translation does not seem to bring about an increase in its indiscriminate use. Moreover, the CG reported using the same or more translation in the FQ than the EG (14/24) despite the monolingual approach to teaching. Finally, the CG used significantly more translation in the FQ for "notes on instructions" and "consulting the teacher" while in the IQ, "retention of new element" and "to check some aspect of writing", which were significant for the EG, decreased slightly in the FQ, whereas the CG reported an increase.

The EG reported that translation favoured ALL significantly in the IQ. However, this decreased (slightly) in the FQ. The CG increased the perception. The CG thought that translation favoured a more relaxed atmosphere in the IQ, but not considerably so. However, there is a significant difference in the FQ regarding the EG, probably because these students realized that translation is not an avoidance or "laziness" strategy, but requires effort. So, to them, it was not more relaxed than other activities.

\subsubsection{Written Protocols (WP) in essays}

Here are the descriptive results of the multiple response question 6 in the $\mathrm{WP}^{11}$ analyzed qualitatively with Atlas.Ti ${ }^{12}$ (94,1\% valid responses). There were 53 responses in WP1 and 52 in WP2. Percentages were analyzed as follows: $25 \%$ responses to a question in each WP was considered relevant for discussion. All the indicators included in the WP (29) appear in the grids below, although the answers were regrouped according to the fluctuation observed in the 10-week interval (No change, Decrease, Increase).

\begin{tabular}{|l|l|l|l|}
\hline \multirow{4}{*}{ No change } & 6a_WHEN & $\%$ & Fluctuation \\
\cline { 2 - 4 } & Write Instructions & 18.8 & $=$ \\
\cline { 2 - 4 } & Consult teacher & 18.8 & $=$ \\
\cline { 2 - 4 } Decrease & Ensure retention of new elements & 25.0 & -5.50 \\
\cline { 2 - 4 } & Plan & $18.8-12.5$ & -18.70 \\
\cline { 2 - 4 } & Self-correct language & $62.5-43.8$ & -6.3 \\
\cline { 2 - 4 } & Check written expression & $31.3-25.0$ & -6.2 \\
\cline { 2 - 4 } & Check written comprehension & $62.5-56.3$ & +12.5 \\
\hline \multirow{3}{*}{ Incease } & Check oral expression & $6.3-18.8$ & +18.8 \\
\cline { 2 - 4 } & Consult classmate & $12.5-31.3$ & +12.5 \\
\cline { 2 - 4 } & Self-correct content & $31.3-50.1$ & \\
\cline { 2 - 4 } & Check oral comprehension & $18.8-31.3$ & \\
\hline
\end{tabular}

"To ensure retention of new elements" was high and did not change, similarly to the results in the questionnaires. "To self-correct language" decreased relevantly whereas "to self-correct content" increased. If read along with other increased indicators, it may be that the students were using it in class for immediate clarifications and for investigating concepts (e.g., parallel texts) rather than for word for word translations. There was a decrease in written expression and comprehension which may mean that they were using more direct writing in the AL.

\footnotetext{
${ }^{11}$ WP_Q6. Please include an example of use of translation from your essay: when, for whom, how and why. Also, please say whether you could have used any other strategy to solve the problem.

${ }^{12}$ ATLAS.ti analyzes written texts, audio, video and graphic data.
} 


\begin{tabular}{|l|l|l|l|}
\hline & 6b_FOR WHOM & $\%$ & Fluctuation \\
\hline No change & Classmate & 6.3 & $=$ \\
\hline Decrease & Myself & $81.3-75$ & -6.3 \\
\hline Increase & Teacher & $18.8-37.5$ & +18.7 \\
\hline
\end{tabular}

The students reported thinking less in L1 and more in AL, as translation decreased "for oneself". Communication with classmates was low with no changes. It increased for the teacher, which may indicate that it was confused with communicating while carrying out the translation activities, as the Teacher's Diary reported a decrease in the use of translation with the teacher after midterm.

\begin{tabular}{|l|l|l|l|}
\hline & 6c - HOW & $\%$ & Fluctuation \\
\hline No change & Bilingual dictionary & 62.5 & \\
\hline Decrease & Google & $56.3-43.8$ & -12.5 \\
\hline & Native or proficient speaker & $18.8-12.5$ & -6.3 \\
\hline Increase & Web search & $56.3-75$ & +18.7 \\
\hline & Teacher & $18.8-25$ & +6.2 \\
\hline & Classmate & $25-31.3$ & +6.3 \\
\hline
\end{tabular}

The students reported a high level of use of bilingual dictionaries, which was refined as the semester proceeded with more accurate web searches and a reduced use of google (although still high). There was a slight increase for consulting with classmates and the teacher. This result is consistent with the fact that students were allowed to use translation for resourcing.

\begin{tabular}{|l|l|l|l|}
\hline & 6d - WHY & $\%$ & Fluctuation \\
\hline No change & Curiosity & 18.8 & $=$ \\
\hline Decrease & Memorizing & $37.5-31.3$ & -6.2 \\
\hline & Others & $18.8-6.3$ & -12.5 \\
\hline Increase & Efficiency & $68.8-100$ & +31.2 \\
\hline & Speed & $12.5-18.8$ & +6.3 \\
\hline
\end{tabular}

"To memorize an expression" was relatively high, there was a slight increase for "speed" and a clear increase for "efficiency", which reached 100\%.

6f. Could you have solved the problem with another strategy (not translation)?

\begin{tabular}{|l|l|l|l|}
\hline & 6f - OTHER STRATEGIES & $\%$ & Fluctuation \\
\hline Decrease & Yes, with more difficulty & $57.1-38.5$ & -18.6 \\
\hline Increase & YES & $14.3-30.8$ & +16.5 \\
\hline & Yes, with less security & $35.7-38.5$ & +2.8 \\
\hline & Yes, but less effectively & $21.4-23.1$ & +1.7 \\
\hline
\end{tabular}

Students reported a self-perceived increased ability to replace translation with other ALL strategies. This was reinforced by the fact that they reported using other strategies without as much difficulty as at the beginning of the course (when they found translation easier to use than other strategies). 
As to when they believed translation to be successful in aiding or improving their ALL process, resulted in the paired t-test which yielded the same high means in both WP, that is, the students in the EG perceived translation to be useful in approximately the same high degree at the beginning and end of the study: 3,29/4 [ $p$ (two-tailed): 1,000].

\begin{tabular}{|l|l|l|l|l|}
\hline & & Mean & Std. deviation & Std. error mean \\
\hline $\begin{array}{l}\text { To what extent did you feel that the } \\
\text { translation was helpful in this case? }\end{array}$ & WP1 & 3.29 & .772 & .187 \\
\cline { 2 - 6 } & WP2 & 3.29 & .686 & .166 \\
\hline
\end{tabular}

\subsubsection{Self-reports (SR) in questionnaires and written protocols (WP)}

The indicator of positions were also categorized through Atlas.Ti (EG) in the SR in the questionnaires and in the WP:

\begin{tabular}{|l|lll|l|}
\hline & VIRTUAL & MAXIMAL & OPTIMAL & Total Responses \\
\hline Initial questionnaire & 5 & 10 & 19 & 34 \\
& $14.71 \%$ & $29.41 \%$ & $55.88 \%$ & \\
\hline Final questionnaire & 3 & 5 & 19 & 27 \\
& $11.11 \%$ & $18.52 \%$ & $70.37 \%$ & \\
\hline
\end{tabular}

The number of students who favoured the Optimal position increased in the EG, although there were still students who preferred the Maximal or Virtual positions.

Here are some examples of students' statements (sic):

OPTIMAL:

SR1. Some teacher think that if you listening the word more times you can understand it better, but if you don't know the meaning you'll never know it.

SR2. It is clear that without the native language and translation at my age I couldn't learn a foreign language.

\section{MAXIMAL}

SR1. To sum up, I think that use of translation it's necessary to translate unknowing words, of course, if the level of the class is not enough. But the teacher cannot used in excess.

SR2. From my point of view, translation is not bad, although when the English level increases and you improve, you should try to reduce translations.

\section{VIRTUAL}

SR1. Although we don't know a word, it's better that the teacher explain it us in en English because if we get used to easy and we always translated word for word instead of understand the whole.

SR2. Many errors when writing and speaking a foreign language happens because the direct translation of our language. 
The entries in TD were analyzed using Atlas.Ti and grouped into three categories from the correspondences established in Table 1 (in section 2.3 above): Cognitive, Metacognitive, Socio-affective. All the following are indicators of the use of translation to solve problems as observed in the learning contexts: 


\begin{tabular}{|c|c|}
\hline COGNITIVE & 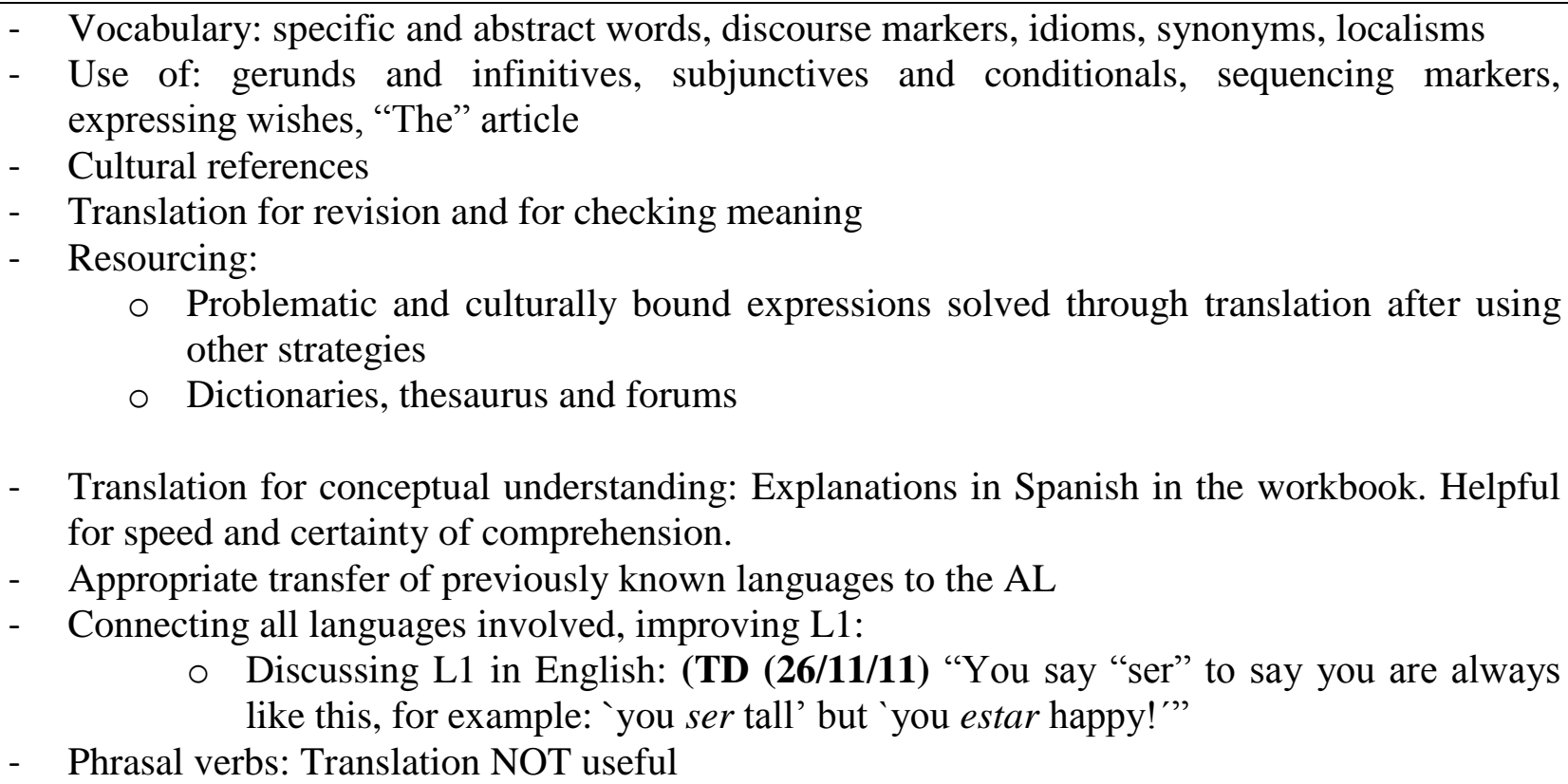 \\
\hline META-COGNITIVE & $\begin{array}{l}\text { - Discuss relationships between } 3 \text { languages (e.g. (non)correspondences) and required } \\
\text { translation strategies to solve problems } \\
\text { - Use of translation strategies to unblock communication in the AL } \\
\text { - ALL strategies (in English). Use of translation when no other possibility is available } \\
\text { - Pertinent questions } \\
\text { - Planning and organizing group discussions in the AL around translation. L1 mainly to clarify } \\
\text { meanings, understand the assignment, plan, spot and solve problems (independent of AL } \\
\text { proficiency) } \\
\text { Students work on text in AL: translation used only as a last resort - except for one student } \\
\text { (insecure) }\end{array}$ \\
\hline SOCIO-AFFECTIVE & $\begin{array}{l}\text { Team work: } \\
\circ \text { Animated group discussions in AL around translation }\end{array}$ \\
\hline
\end{tabular}




\begin{tabular}{|c|c|}
\hline & $\begin{array}{l}\text { Participation of all students (including shy or weaker students not confident to } \\
\text { participate in general discussions usually) } \\
\text { - } \begin{array}{l}\text { Self-concept: Confident use of linguistic background to transfer knowledge from previously } \\
\text { known languages to the AL }\end{array} \\
\text { - Receiving and responding to phenomena } \\
\circ \text { Reflecting on linguistic backgrounds: Surprise at linguistic knowledge of } \\
\text { classmates, interest, asking questions, etc. in English } \\
\circ \quad \text { Social use of translation: Awareness of influence of translation in real life } \\
\text { (restaurants, ads, etc.) and published texts } \\
\text { - Activating interpersonal skills: } \\
\circ \text { Ludic atmosphere during translation activities } \\
\circ \quad \text { Suggest a party with the recipes prepared by them (Catalan, Galician, Majorcan, } \\
\text { British)- last day } \\
\circ \text { Active and smiling even after challenging activities, good questions } \\
\circ \begin{array}{l}\text { Expressing feelings: TD (26/10/11) "I hate cheese, but cabra cheese...!! It's more } \\
\text { cabra cheese in Spanish..." (cabra=goat) }\end{array}\end{array}$ \\
\hline
\end{tabular}

Table 3. Learning indicators in the Teacher's Diary 
Critical incidents were also recorded from indicators in the list of educational objectives, learning strategies and translation competences. Two critical moments were observed. The first occurred at the beginning of the semester, which could be attributed to the novelty of the connectivist instruction and to the anxiety reducing effect of using one's own language: e.g., TD (21/9/11) fa remoure això, eh? and touches head. [tr. this stirs you up, doesn't it?], followed by general smiles and nodding agreement. The second took place at midterm, suggesting a turning point in the comprehension and use of translation: e.g., TD (26/11/11) "Translation strategies to unblock communication: used unaware, in groups, without asking me, naming them naturally, as one other possible strategy - not the only one! I asked: did you have to use translation? They answered they didn't, but that they had used strategies to get the expression or word 'we can use the translation strategies when we're blocked'-translation strategies mixed naturally amongst other AL strategies!”.

At the end of the semester, all strategies seemed to converge, indicating perhaps that the use of translation for ALL had become a normalized behaviour: e.g., TD (2/11/11) Jo crec que és una activitat molt interactiva $i$ en la qual podem improve el nostre coneixement de forma més específica i concreta. I és una forma divertida i amena per aprendre (sic)[tr. I think it's a very interactive activity where we can improve our knowledge in a more specific and concrete way. And it's a fun and entertaining way to learn].

\section{Conclusions and further research}

This paper set to explore the role of translation in ALL according to the perceptions and observations recorded by the participating students and teacher. Statistics were included in the final report to weigh the results against other data. Two naturally occurring groups participated so as to contrast the results according to whether translation had been incorporated into the syllabus (EG) or not (CG). The study was based on the assumption that a plurilingual paradigm is beneficial for ALL as opposed to a monolingual approach. A theoretical background has been suggested to support this assumption (TOLC). As the number of students was not high (45), our conclusions are tentative. However, some general tendencies can be detected from the analysis of the results of the study and these are worth being explored in further research.

Regarding the theoretical background, the underlying principles of the Direct Method were questioned and found lacking as, on the one hand, the results revealed that an informed use of translation did not increase its indiscriminate use in ALL. Also, the use of translation as a spontaneous learning strategy confirmed that, if presented explicitly, it may not only not hinder improvement of AL, but even be beneficial. In fact, the use of translation either remained even or decreased. Besides, more translation resulted in more reported use of AL. The students stated that they used less translation as well as less translation "for oneself" and more other ALL strategies as the semester advanced. It may be that connecting knowledge in the brain which is coherent with their maturational stage and their declarative and procedural knowledge levels (cf. the Anatomical Model of Language Learning in section 2.2) triggered other strategies and skills in accordance with the notion of multi-competence and complexity theory.

Moreover, translation was used alongside other ALL strategies. The EG used less translation-and more efficiently-at the end of the semester, especially when compared 
to the CG where no L1 or translation were allowed and where the participants reported that they had used less L1 and translation than participants in the EG. These used AL increasingly with strategies such as guessing through context or searching for synonyms.Translation was used as a last resort, especially after midterm. It was deemed useful mainly for efficiency, accuracy, certainty (checking and retaining meaning), speed and revision, for the understanding of certain grammatical and lexical items and for comparing and solving problems regarding cultural references. It was also used to discuss issues regarding the L1(s), thus reinforcing the validity of the Interdependence hypothesis and bidirectional interlinguistic awareness. Both groups clearly accepted translation as a natural learning strategy at the beginning and at the end of the semester. Their perceptions and use of translation as a valuable ALL tool did not diminish significantly during the whole semester. However, translation was not useful for all aspects of language learning, especially those which involved very different or very similar structures or conceptual frameworks across languages, which could favour interference. Resourcing was useful to solve these cases.

As for classroom dynamics, the EG reported a slight decrease in "favours a relaxed atmosphere" and "favours ALL". This could be because, after midterm, translation stopped being a novelty and became a natural part of the learning context, i.e., one more learning strategy. Also, instead of being perceived as an avoidance strategy, its complexity was acknowledged. Two unexpected findings emerged. On the one hand, translation strategies were judged useful for unblocking communication in AL. These strategies, which are usually included in translation competence lists (e.g., explicitation, domestication, foreignisation) were used to improve communication in AL without using the L1. On the other hand, an interrelated use of strategies became natural, as the students were also using ALL strategies such as paraphrasing to arrive at appropriate translations.

The attempt to establish correspondences between educational objectives, ALL strategies and translation competences to observe how, when and why translation is used to improve ALL was successful and supported by data that suggest the following classification of indicators as appropriate: cognitive, metacognitive and socioaffective learning strategies. More work is needed to fine tune these correspondences.

Results from the Teacher's Diary also revealed that resourcing skills improved as the students moved away from exclusive use of bilingual dictionaries and became aware of more professional possibilities. Also, focused sessions and tutorials to reflect on translation definitions, strategies, competences and problem-solving related to the assignments were decisive, as observed in the turning point regarding comprehension and appropriate use at midterm. This explicit focus favoured an increased awareness of nature and potential of translation, its continuous social use and the acquisition of an informed critical attitude. However, not all students accepted an Optimal position regarding the use of translation in ALL. Also noteworthy is that it was the most insecure student who insisted in translating very frequently. Some contradictory statements in the self-reports (especially regarding translation as an aid for grammar) suggest observing possible correlations between learning styles and positions, perceptions and use of translation in the future.

In consonance with the humanistic and socioconstructivist approach to learning, translation was found to strengthen team work, enable the active participation of all 
learners regardless of their learning style and raise awareness of the benefits engendered by their rich linguistic and cultural backgrounds. The activities yielded positive reactions and performance thus indicating in which direction the design of learning materials should go, probably combining pedagogic translation activities for awareness raising with projects that favour the use translation in authentic situations. These should be blended ecologically within the course syllabus. In all cases, the use of translation was independent of the students' AL proficiency. This suggests that informed translation activities may be beneficial at all levels of linguistic competence. On the whole, a plurilingual paradigm and pedagogical practices revolving around humanistic and socioconstructivist approaches to learning seem to provide an appropriate framework for the study of the role of translation in Additional Language Learning as a notable example of TOLC.

\section{MARIA GONZÁLEZ DAVIES}

Universitat Ramon Llull, Barcelona, Spain.

mariagd@blanquerna.url.edu.

\section{References}

Anderson, Lorin and David Krathwohl (eds) (2001) Taxonomy for Learning, Teaching, and Assessing. A Revision of Bloom's Taxonomy of Educational Objectives, (2nd edition), New York: Longman.

Aronin, Lisa and Britta Hufeisen (eds) (2009) The Exploration of Multilingualism, Amsterdam \& New York: John Benjamins.

Aronin, Larissa and David Singleton (2012) Multilingualism, Amsterdam \& New York: John Benjamins.

Bialystok, Ellen (2001) Bilingualism in Development: Language, Literacy and Cognition, Cambridge: Cambridge University Press.

---- (2009) 'Bilingualism: The Good, the Bad and the Indifferent', Bilingualism: Language and Cognition 12(1): 3-11.

Bialystok, Ellen and Kenji Hakuta (1999) 'Confounded Age: Linguistic and Cognitive Factors and Age Differences for Second Language Acquisition', in David Birdsong (ed.) Second Language Acquisition and the Critical Period Hypothesis, Mahwah, Nj: Erlbaum, 161-181.

Bialystok, Ellen, Gigi Luk and Ernest Kwan (2005) 'Bilingualism, Biliteracy, and Learning to Read: Interactions among Languages and Writing Systems', Scientific Studies of Reading 9: 43-61.

Bloom, Benjamin (1956) Taxonomy of Educational Objectives. Handbook I: The Cognitive Domain, New York: David McKay Co Inc.

Burke R. Johnson, Anthony J. Onwuegbuzie and Lisa A. Turner (2007) 'Toward a Definition of Mixed Methods Research', Journal of Mixed Methods Research 1: 112133.

Byram, Michael (2008) From Foreign Language Education to Education for International Citizenship. Essays and Reflections, Clevedon: Multilingual Matters.

Cohen, Andrew (2011) Strategies in Learning and Using a Second Language, Edinburgh: Pearson Education Limited.

Cook, Guy (2010) Translation in Language Teaching: An Argument for Reassessment, Oxford: Oxford University Press.

Cook, Vivien (2001) 'Using the First Language in the Classroom', Canadian Modern Language Review 57(3): 184-206. 
-- (2007) 'Multi-Competence: Black Hole or Wormhole?', in Zhaohong Han and Eun Sun Park (eds) Understanding Second Language Process, Bristol: Multilingual Matters, 16-26.

Corcoll, Cristina (2011) “"English Spelling is Weird”: Developing Children's Language Awareness', International Journal of Multilingualism 10(1): 27-45.

Council of Europe (2001) Common European Framework of Reference for Languages: Learning, Teaching, Assessment, Cambridge: Cambridge University Press. Available at URL: http://www.coe.int/t/dg4/linguistic/Source/Framework_EN.pdf.

Crystal, David (2009) Just a Phrase I'm Going Through. My Life in Language. London and New York: Routledge.

Cummins, James (1979) 'Cognitive/Academic Language Proficiency, Linguistic Interdependence, the Optimum Age Question and Some Other Matters', Working Papers on Bilingualism 19: 121-129.

----- (1984) 'Wanted: a Theoretical Framework for Relating Language Proficiency to Academic Achievement among Bilingual Students', in Charlene Rivera (ed.) Language Proficiency and Academic Achievement, Clevedon: Multilingual Matters.

----- (2007) 'Rethinking Monolingual Instructional Strategies in Multilingual Classrooms', Canadian Journal Of Applied Linguistics 10(2): 221-240.

----- (2008) 'Teaching for Transfer: Challenging the Two Solitudes Assumption in Bilingual Education', in James Cummins and Nancy Hornberger (eds) Encyclopedia of Language and Education (2nd edition), (5), New York: Springer Science, 65-77.

González Davies, Maria (2004) Multiple Voices in the Translation Classroom. Activities, Tasks and Projects, Amsterdam \& Philadelphia: John Benjamins.

----- (2011) 'Engaging Future Generations in Multicultural Projects Through the Translation of Literature for Young Readers', in Philipe Clermont and Britta Benert (eds) Contre l'innocence - Esthétique de l'engagement en littérature de jeunesse, Bern: Peter Lang, 439-451.

- (2012a) 'The Role of Translation in Other Learning Contexts: Towards Acting Interculturally', in Michael Borodo and Sévérine Hubscher-Davidson (eds) Global Trends in Translator and Interpreter Training: Mediation and Culture, London: Continuum, 150-160.

----- (2012b) 'Translating for Other Learning Contexts: The L1 and Translation in Foreign Language Learning', in Marcos Cánovas, Gemma Delgar, Lucrecia Keim, Sarah Khan and Àngels Pinyana (eds) Challenges in Language and Translation Teaching in the Web 2.0 Era, Granada: Comares, 65-74.

González Davies, Maria and Christopher Scott-Tennent (2001) 'Training in the Application of Translation Strategies for Undergraduate Scientific Translation Students', Meta 46(4): 737-744.

-- (2005) 'A Problem-Solving and Student-Centred Approach to the Translation of Cultural References', Meta 50(1): 160-179.

----- (2009) 'Back to Mother...Tongue. L1 and Translation as Aids to FLA in a CLIL Context'. Paper presented at the Conference on First and Second Languages: Exploring the Relationship in Pedagogy-Related Contexts, University of Oxford, 27-28 March 2009. Available at URL: http://www.education.ox.ac.uk/research/appliedinguistics/events/events-archive/.

Hall, Graham and Guy Cook (2012) 'Own-language Use in Language Teaching and Learning: State of the Art'. Language Teaching 45(3): 271-308.

Hamers, Josiane F. and Michel H. Blanc (1989/2000) Bilinguality and Bilingualism, $\left(2^{\text {nd }}\right.$ edition), Cambridge: Cambridge University Press. 
Hatim, Basil and Ian Mason (1990) Discourse and the Translator, London \& New York: Routledge.

Herdina, Philipe and Ulrike Jessner (2002) A Dynamic Model of Multilingualism. Perspectives of Change in Psycholinguistics, Clevedon: Multilingual Matters.

House, Juliane (2009) 'Moving across Languages and Cultures in Translation and Intercultural Communication', in Kristin Bührig, Juliane House and Jan D. ten Thije (eds) Translational Action and Intercultural Communication, Manchester: St Jerome.

Kelly, Dorothy (2005) A Handbook for Translator Trainers, Manchester: St. Jerome.

Kovelman, Ioulia, Stephanie A. Baker and Laura-Ann Petitto (2008) 'Bilingual and Monolingual Brains Compared: A Functional Magnetic Resonance Imaging Investigation of Syntactic Processing and a Possible "Neural Signature" of Bilingualism', Journal of Cognitive Neuroscience 20(1): 153-169.

Macaro, Ernesto (2001) 'Analysing Student Teachers' Codeswitching in Foreign Language Classrooms: Theories and Decision Making’, Modern Language Journal 85(4): 531548.

(2006) 'Strategies for Language Learning and for Language Use: Revising the Theoretical Framework', Modern Language Journal 90(3): 320-37.

McMillan, Brian and Damian Rivers (2011) 'The Practice of Policy: Teacher Attitudes toward "English Only"', System 39(2): 251-263.

O’Malley, Michael and Anna Uhl Chamot (1990) Learning Strategies in Second Language Acquisition, Cambridge: Cambridge University Press.

Oxford, Rebecca L. (1990) Language Learning Strategies: What Every Teacher Should Know, New York: Newbury House.

----- (2011) Teaching and Researching Language Learning Strategies, Edinburgh: Pearson Education Limited.

Pettito, Laura-Ann (2009) 'New Discoveries from the Bilingual Brain and Mind Across the Life Span: Implications for Education', Mind, Brain, and Education 3(4):185-197.

Richards, Jack C. and Theodore S. Rodgers (1986/2001) Approaches and Methods in Language Teaching, London and New York: Routledge.

Scott-Tennent, Christopher and Maria González Davies (2008) 'Effects of Specific Training on the Ability to Deal with Cultural Referents in Translation', Meta 53(4): 782798.

Shavit, Zohar (1986/2009) Poetics of Children's Literature, Athens \& Georgia: University of Georgia Press.Skinner, David (1985) 'Access to Meaning: The Anatomy of the Learning/Language Connection', Journal of Multilingual and Multicultural Development 6(2): 97-116. 


\section{APPENDIX I: QUESTIONNAIRES}

Table A. Independent samples t-test

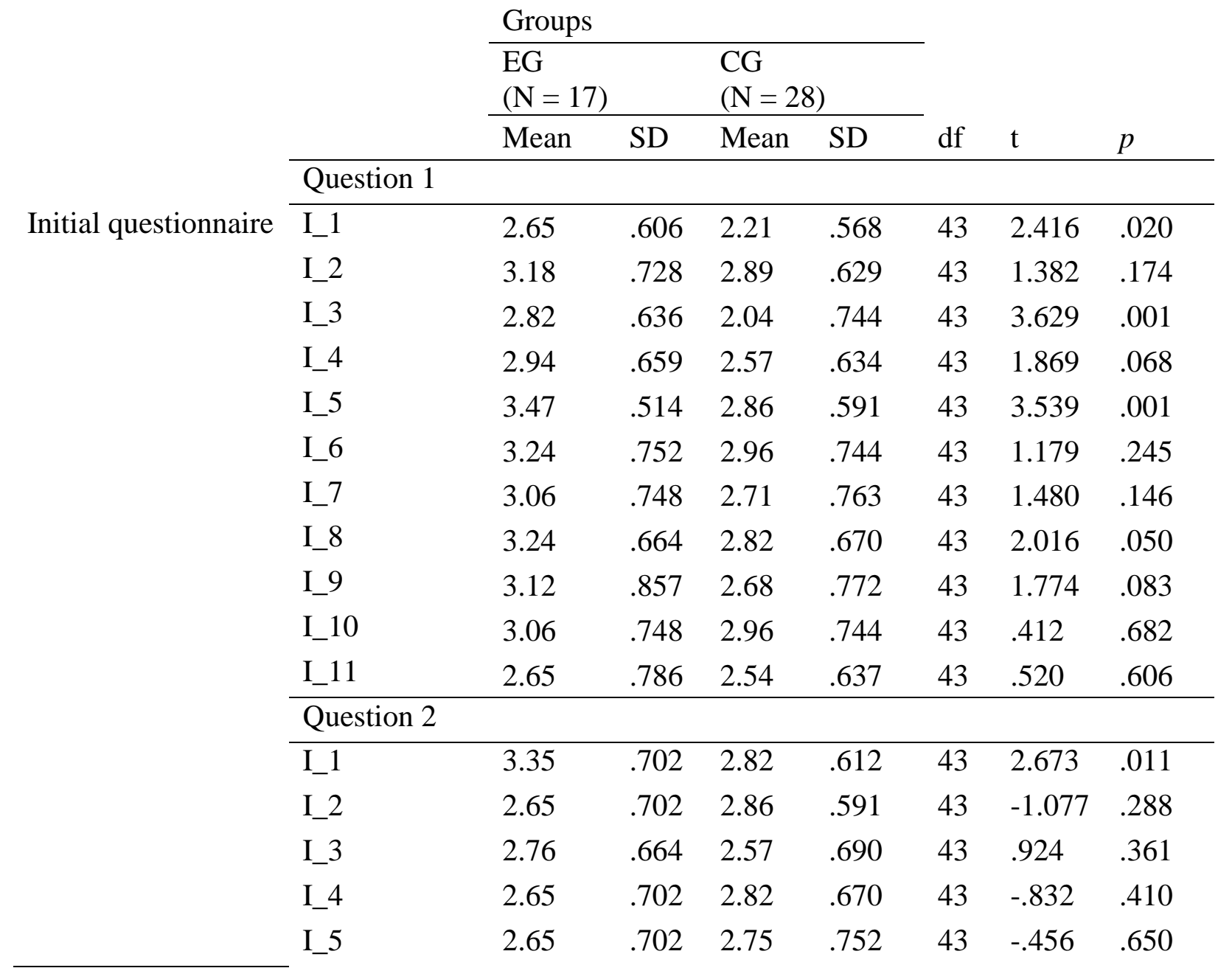




\begin{tabular}{|c|c|c|c|c|c|c|c|c|}
\hline & I_6 & 2.88 & .781 & 2.82 & .670 & 43 & .278 & .782 \\
\hline & I_7 & 2.35 & .786 & 2.57 & .742 & 43 & -.937 & .354 \\
\hline & I_8 & 3.29 & .470 & 3.18 & .670 & 43 & .623 & .536 \\
\hline & I_9 & 2.82 & .636 & 2.93 & .604 & 43 & -.554 & .582 \\
\hline & I_10 & 3.14 & .535 & 3.00 & .609 & 40 & .745 & .460 \\
\hline & I_11 & 2.76 & .752 & 2.75 & .645 & 43 & .070 & .945 \\
\hline & I_12 & 2.94 & .429 & 2.75 & .441 & 43 & 1.425 & .161 \\
\hline & I_13 & 2.88 & 697 & 2.71 & .600 & 43 & .857 & .396 \\
\hline & Ques & & & & & & & \\
\hline \multirow[t]{15}{*}{ Final questionnaire } & I_1 & 2.06 & .659 & 2.71 & .763 & 43 & 2.937 & .005 \\
\hline & I_2 & 2.65 & .606 & 2.93 & .766 & 43 & -1.288 & .205 \\
\hline & I_3 & 2.12 & .600 & 2.61 & .832 & 43 & -2.112 & .041 \\
\hline & I_4 & 2.41 & .507 & 2.71 & .600 & 43 & -1.735 & .090 \\
\hline & I_5 & 2.76 & .664 & 3.00 & .471 & 43 & -1.389 & .172 \\
\hline & I_6 & 2.71 & .772 & 2.86 & .705 & 43 & -.673 & .504 \\
\hline & I_7 & 2.82 & .728 & 2.68 & .772 & 43 & .624 & .536 \\
\hline & I_8 & 2.94 & .659 & 2.86 & .705 & 43 & .397 & .693 \\
\hline & I_9 & 2.76 & .664 & 2.64 & .731 & 43 & .561 & .578 \\
\hline & I_10 & 2.29 & .686 & 2.93 & .663 & 43 & -3.073 & .004 \\
\hline & I_11 & 2.12 & .781 & 2.57 & .790 & 43 & -1.876 & .067 \\
\hline & Ques & & & & & & & \\
\hline & I_1 & 2.94 & .748 & 2.96 & .693 & 43 & -.105 & .917 \\
\hline & I_2 & 2.65 & .702 & 2.86 & .705 & 43 & -.971 & .337 \\
\hline & I_3 & 2.59 & .712 & 2.82 & .905 & 43 & -.905 & .317 \\
\hline
\end{tabular}




$\begin{array}{llllllll}\text { I_4 } & 2.29 & .470 & 2.82 & .612 & 43 & -3.045 & .004 \\ \text { I_5 } & 2.88 & .697 & 2.89 & .737 & 43 & -.047 & .963 \\ \text { I_6 } & 2.53 & .874 & 2.93 & .766 & 43 & -1.606 & .116 \\ \text { I_7 } & 2.24 & .752 & 2.46 & .744 & 43 & -.996 & .325 \\ \text { I_8 } & 2.94 & .748 & 2.89 & .567 & 43 & .246 & .807 \\ \text { I_9 } & 2.76 & .831 & 2.89 & .629 & 43 & -.586 & .561 \\ \text { I_10 } & 2.94 & .748 & 2.89 & .629 & 43 & .233 & .817 \\ \text { I_11 } & 2.53 & .943 & 2.71 & .659 & 43 & -.774 & .443 \\ \text { I_12 } & 2.65 & .786 & 2.71 & .600 & 43 & -.324 & .748 \\ \text { I_13 } & 2.76 & .752 & 2.89 & .685 & 43 & -.586 & .561\end{array}$

\section{Table B. Paired samples t-test}

\begin{tabular}{|c|c|c|c|c|c|c|c|c|}
\hline \multirow{11}{*}{$\mathrm{EG}(\mathrm{N}=17)$} & & \multicolumn{4}{|c|}{ Questionnaires } & \multirow[b]{3}{*}{$\mathrm{df}$} & \multirow[b]{3}{*}{$\mathrm{t}$} & \multirow[b]{3}{*}{$p$} \\
\hline & & \multicolumn{2}{|l|}{ Initial } & \multicolumn{2}{|l|}{ Final } & & & \\
\hline & & Mean & SD & Mean & SD & & & \\
\hline & Question 1 & & & & & & & \\
\hline & I_1 & 2.65 & .606 & 2.06 & .659 & 16 & 2.787 & .013 \\
\hline & I_2 & 3.18 & .728 & 2.65 & .606 & 16 & 2.314 & 0.34 \\
\hline & I_3 & 2.82 & .636 & 2.12 & .600 & 16 & 3.429 & .003 \\
\hline & I_4 & 2.94 & .659 & 2.41 & .507 & 16 & 2.729 & .015 \\
\hline & I_5 & 3.47 & .514 & 2.76 & .664 & 16 & 3.429 & .003 \\
\hline & I_6 & 3.24 & .752 & 2.71 & .772 & 16 & 2.045 & .058 \\
\hline & I_7 & 3.06 & .748 & 2.82 & .728 & 16 & 1.074 & .299 \\
\hline
\end{tabular}




\begin{tabular}{lllllllll}
\hline & I_8 & 3.24 & .664 & 2.94 & .659 & 16 & 1.231 & .236 \\
I_9 & 3.12 & .857 & 2.76 & .664 & 16 & 1.461 & .163 \\
I_10 & 3.06 & .748 & 2.29 & .686 & 16 & 3.490 & .003 \\
& I_11 & 2.65 & .786 & 2.12 & .781 & 16 & 1.941 & .070 \\
\hline & & & & & & & \\
\hline & Question 2 & & & & & & \\
& I_1 & 3.35 & .702 & 2.94 & .748 & 16 & 1.807 & .090 \\
I_2 & 2.65 & .702 & 2.65 & .702 & 16 & .000 & 1.000 \\
& I_3 & 2.76 & .664 & 2.59 & .712 & 16 & .899 & .382 \\
& I_4 & 2.65 & .702 & 2.29 & .470 & 16 & 1.852 & .083 \\
I_5 & 2.65 & .702 & 2.88 & .697 & 16 & -1.167 & .260 \\
I_6 & 2.88 & .781 & 2.53 & .874 & 16 & 1.144 & .269 \\
& I_7 & 2.35 & .786 & 2.24 & .752 & 16 & .439 & .632 \\
I_8 & 3.29 & .470 & 2.94 & .748 & 16 & 1.461 & .163 \\
& I_9 & 2.82 & .636 & 2.76 & .831 & 16 & .293 & .773 \\
I_10 & 3.14 & .535 & 2.86 & .770 & 16 & 1.075 & .302 \\
I_11 & 2.76 & .752 & 2.53 & .943 & 16 & 1.074 & .299 \\
I_12 & 2.94 & .429 & 2.65 & .786 & 16 & 1.319 & .206 \\
I_13 & 2.88 & .697 & 2.76 & .752 & 16 & .460 & .651 \\
\hline Question 1 & & & & & & & \\
\hline I_1 & 2.21 & .568 & 2.71 & .763 & 27 & -3.000 & .006 \\
I_2 & 2.89 & .629 & 2.93 & .766 & 27 & -.197 & .846 \\
I_3 & 2.04 & .744 & 2.61 & .832 & 27 & -3.032 & .005 \\
I_4 & 2.57 & .634 & 2.71 & .600 & 27 & -.941 & .355 \\
I_5 & 2.86 & .591 & 3.00 & .471 & 27 & -1.000 & .326
\end{tabular}




\begin{tabular}{llllllll}
\hline I_6 & 2.96 & .744 & 2.86 & .705 & 27 & .619 & .541 \\
I_7 & 2.71 & .763 & 2.68 & .772 & 27 & .197 & .846 \\
I_8 & 2.82 & .670 & 2.86 & .705 & 27 & -.273 & .787 \\
I_9 & 2.68 & .772 & 2.64 & .731 & 27 & .297 & .769 \\
I_10 & 2.96 & .744 & 2.93 & .663 & 27 & .205 & .839 \\
I_11 & 2.54 & .637 & 2.57 & .790 & 27 & -.189 & .851 \\
\hline Question 2 & & & & & & & \\
\hline I_1 & 2.82 & .612 & 2.96 & .693 & 27 & -.891 & .381 \\
I_2 & 2.86 & .591 & 2.86 & .705 & 27 & .000 & 1.000 \\
I_3 & 2.57 & .690 & 2.82 & .905 & 27 & -1.230 & .229 \\
I_4 & 2.82 & .670 & 2.82 & .612 & 27 & .000 & 1.000 \\
I_5 & 2.75 & .752 & 2.89 & .737 & 27 & -.750 & .460 \\
I_6 & 2.82 & .670 & 2.93 & .766 & 27 & -.619 & .541 \\
I_7 & 2.57 & .742 & 2.46 & .744 & 27 & .827 & .415 \\
I_8 & 3.18 & .670 & 2.89 & .567 & 27 & 1.867 & .073 \\
I_9 & 2.93 & .604 & 2.89 & .629 & 27 & .225 & .823 \\
I_10 & 3.00 & .609 & 2.89 & .629 & 27 & .721 & .477 \\
I_11 & 2.75 & .645 & 2.71 & .659 & 27 & .273 & .787 \\
I_12 & 2.75 & .441 & 2.71 & .600 & 27 & .297 & .769 \\
I_13 & 2.71 & .600 & 2.89 & 685 & 27 & -1.095 & .283
\end{tabular}


